Quaestio Iuris

vol.05, $n^{\circ}$ 02. ISSN 1516-0351

\title{
Judicialização da Política e Representação Funcional no Brasil Contemporâneo: uma ameaça à soberania popular? / Legalization of Politics and Functional Representation in Contemporary Brazil: a threat to popular sovereignty ${ }^{1}$
}

Luiz Eduardo Motta $^{2}$

\section{Resumo}

No presente artigo busca analisar o fenômeno da judicialização da política e as suas consequências, como o fortalecimento das representações funcionais estatais e como a crise das representações políticas tradicionais, como os partidos políticos.

O texto chega à conclusão de que o Estado e o conjunto de suas instituições estão em uma perspectiva relacional, entendendo-os como arenas de lutas entre as classes e grupos sociais e permeados de contradições e conflitos, a partir da definição de Poulantzas sobre o Estado e sobre o direito moderno.

Palavras-chave: Judicialização da política. Representação funcional. Crise da representação política. Poulantzas. Lutas de grupos sociais.

\begin{abstract}
The present paper analyzes the phenomenon of judicialization of politics and its consequences, such as strengthening state and functional representations as conventional political representations, such as political parties.

\footnotetext{
${ }^{1}$ Este artigo é uma versão ampliada e modificada do trabalho apresentado no XIV Congresso Brasileiro de Sociologia (SBS) e no XXVII Congresso ALAS 2009. Agradeço os comentários sobre o texto, especialmente de Marco Aurélio Nogueira e Carla Giani Martelli (SBS) e Martha Diaz Villegas e Marcelo Pereira de Mello (ALAS).

${ }^{2}$ Sociólogo, Doutor em Sociologia pelo IUPERJ, Mestre em Sociologia e Antropologia pelo IFCS-UFRJ, Professor Adjunto de Ciência Política do Instituto de Filosofia e Ciências Sociais da Universidade Federal do Rio de Janeiro - IFCS-UFRJ.
}

Revista Quaestio Iuris, vol.05, nº1. ISSN 1516-0351 p. 256-285 256 


\section{Quaestio Iuris}

vol.05, $\mathrm{n}^{\circ}$ 02. ISSN 1516-0351

The text concludes that the State and all its institutions are in a relational perspective, understanding them as arenas of struggle between classes and social groups and permeated with contradictions and conflicts, from the definition of Poulantzas's of State and of modern law.

Keywords: Judicialization of politics. Functional representation. Crisis of political representation. Poulantzas. Struggles of social groups.

\section{Introdução}

Esse artigo visa analisar o fenômeno da judicialização da política e as suas consequiências como o fortalecimento das representações funcionais estatais do direito (a exemplo do Ministério Público, da Magistratura, da Defensoria Pública, além de outras agências estatais) mediante a crise das representações políticas tradicionais, como os partidos políticos. O artigo propõe fazer um mapeamento das posições favoráveis ou críticas ao tema que, ou percebem na judicialização a criação de novos canais de representação da sociedade e de exercício de cidadania (C.Neal Tate e T. Vallinder, John Ferejohn, Werneck Vianna, Tereza Sadek) ou as que apontam a judicialização e as representações funcionais uma ameaça à soberania popular (Antoine Garapon, Andréas Kalyvas, Rogério Arantes entre outros), além da possibilidade de formação de uma oligarquia (ou elite) que tutelaria os interesses da sociedade, expressando uma nova forma de autoritarismo estatal, que ao invés de se manifestar no poder executivo, como observou Poulantzas nos anos 1970, encontrar-se-ia no poder judiciário e nas representações funcionais do direito estatal.

$\mathrm{O}$ artigo se divide em quatro partes: a primeira aborda o significado do conceito de judicialização; em seguida, trata da crise de representação política e a ascensão da representação funcional como conseqüência do fenômeno da judicialização política, criando novos canais de absorção de demandas populares por meio das instituições do 


\section{Quaestio Iuris}

vol.05, $\mathrm{n}^{\circ}$ 02. ISSN 1516-0351

direito estatal; a terceira expõe as críticas ao processo de judicialização como uma ameaça à soberania popular e expressando uma nova forma de autoritarismo estatal; por fim, a conclusão que percebe o Estado e o conjunto de suas instituições (ou aparelhos) numa perspectiva relacional, entendendo-os como arenas de lutas entre as classes e grupos sociais e permeados de contradições e conflitos, a partir da definição de Poulantzas sobre o Estado e o direito moderno.

\section{1) Crise de representação política e a emergência da judicialização}

A crise da representação política já tem sido, desde os anos 1970, alvo de reflexão da sociologia política a exemplo das observações de Nicos Poulantzas, nas quais apontava o fortalecimento do poder executivo diante o legislativo, na medida em que os partidos políticos tornavam-se cada vez mais correias de transmissão de interesses do governo (1978). Um exemplo da crise de representação dos partidos políticos foi o fim dos dois partidos mais tradicionais da Itália, o Partido Comunista Italiano e o Democrata Cristão.

Atualmente o que se percebe - desde os anos 1990 - é o fortalecimento do judiciário e dos atores jurídicos em relação à representação política do legislativo, e mesmo em alguns casos do executivo. Isso tem sido denominado por parte dos cientistas sociais como judicialização. O fenômeno da judicialização política e social acaba por superar a afirmação de Montesquieu no Espírito das Leis de que o poder judiciário era nulo ${ }^{3}$. Redefinidos os atores jurídicos, têm-se efetivamente desde os anos 1990 um papel importante ocupado pelo Ministério Público e a Magistratura, como também de outras instituições do direito estatal como a Defensoria Pública.

Segundo Tate e Vallinder, a judicialização da política (e das relações sociais) expressa, com efeito, uma nova tendência da democracia contemporânea. Embora haja semelhanças, a judicialização não se confunde com a corrente do "uso alternativo" do direito, pois o ativismo dos operadores do direito não é necessariamente condicionado, de modo subjetivo, por uma perspectiva de esquerda, em defesa dos setores subalternos da sociedade capitalista. O fenômeno da judicialização, de acordo com C. Neal Tate, é próprio ao sistema

\footnotetext{
3 “[...] o poder de julgar, tão terrível entre os homens, não estando ligado nem a uma certa situação, nem a uma certa profissão, torna-se, por assim dizer, invisível e nulo" (MONTESQUIEU, 1982: p. 188).
}

Revista Quaestio Iuris, vol.05, $\mathrm{n}^{\circ} 01 . \mathrm{ISSN} 1516-0351$ p. 256-285 258 


\section{Quaestio Iuris}

vol.05, $\mathrm{n}^{\circ}$ 02. ISSN 1516-0351

democrático, pois seria mais difícil a presença da mesma num sistema autoritário ou totalitário, haja vista que nesses sistemas políticos caracterizam-se pela concentração de poder pelo executivo. Além do sistema democrático procedural, Tate destaca outros elementos que corroboram a formação da judicialização política, como a separação de poderes, a política de direitos, a pressão dos grupos de interesses e as Cortes Supremas e, sobretudo, o ativismo judicial (TATE, 1995: p. 28-29).

Para John Ferejohn (2004: p 46), o conceito de judicialização da política indica a profunda transformação que vem ocorrendo desde o final da II Guerra Mundial, pois, como afirma,

(...)observa-se um profundo deslocamento do poder do Legislativo para tribunais e outras instituições jurídicas. Tal deslocamento - que recebeu o nome de judicialização - tem ocorrido em escala mais ou menos global. O espetáculo dos juízes italianos pondo abaixo o sistema de troca-troca de gabinetes estabelecido na Itália no pós-guerra, magistrados franceses caçando primeiros-ministros e presidentes, e até mesmo juízes tomando a iniciativa de prender e julgar ex-ditadores e líderes militares, são os aspectos mais visíveis dessa tendência. Mesmo a intervenção da Suprema Corte americana na disputa eleitoral em Bush v. Gore é outra manifestação bastante conhecida desta tendência

De fato, afirmar que a política estaria confinada ao processo legislativo e a seus atores tradicionais (partidos políticos, por exemplo) seria bastante simplista. Como afirma Ferejohn (p.47), reconhecemos que os tribunais têm sido cada vez mais capazes e propensos a limitar e regular o poder das instituições legislativas, e isso significa que os tribunais progressivamente têm se tornado os espaços públicos em que as políticas públicas são feitas e nos quais os juízes têm estado cada vez mais dispostos a regular a ação da atividade política. Ferejohn relembra Tocqueville, de A Democracia na América, em que o pensador francês já percebia essa tendência das instituições judiciárias na democracia moderna e, com efeito, se tornou difundida nas democracias contemporâneas: "Esse crescente papel dos tribunais, tanto na formulação de políticas quanto na atividade política, significa um fenômeno que Tocqueville já identificara na política americana anos atrás, hoje tornou-se global: a transformação de questões políticas em questões jurídicas". (FEREJOHN:p. 47).

Revista Quaestio Iuris, vol.05, no01. ISSN 1516-0351 p. 256-285 259 


\section{Quaestio Iuris}

vol.05, $\mathrm{n}^{\circ}$ 02. ISSN 1516-0351

Para Farejohn os tribunais têm sido cada vez mais capazes e propensos a limitar e regular o poder das instituições legislativas, e isso significa que os tribunais progressivamente têm se tornado os espaços públicos nos quais as políticas públicas são feitas e os juízes têm estado cada vez mais dispostos a regular a ação da atividade política. Há, de acordo com Ferejohn duas causas gerais para o surgimento da judicialização: primeiramente, a crescente fragmentação do Poder Legislativo, que limita sua capacidade de legislar sobre as políticas públicas e os programas de governo, o que leva as pessoas a migrarem a resolução de seus conflitos para outras instituições das quais buscam soluções. Os tribunais, em geral, têm sido esses espaços institucionais. Em segundo, os tribunais (pelo menos certos tribunais) têm tido amplo alcance para proteger valores e direitos contra abusos do poder político. Conforme observa Ferejohn: "Em outras palavras, à medida que o público perde confiança na capacidade do Legislativo legislar de acordo com seus interesses, suas esperanças e desejos se voltam aos tribunais" (FEREJOHN: p.48).

Com efeito, o fenômeno da judicialização da política e das relações sociais emerge nos anos 90 na formação social brasileira devido tanto aos princípios e dispositivos constitucionais que fortaleceram as instituições judiciais, como a crise de representação política que acabou por revigorar as representações funcionais, especialmente os membros do Ministério Público, e seguindo atrás os defensores públicos e os magistrados (ARANTES,2000; WERNECK VIANNA e BURGOS 2002; MOTTA 2008).

Embora a problemática da judicialização seja, atualmente, objeto de investigação e reflexão por parte do pensamento sociopolítico contemporâneo, a exemplo de Vallinder, Nate, Garapon, e o já citado Ferejohn, a expansão do Poder Judiciário e a crise de representação do Poder Legislativo, além da crise fiscal do Executivo, já vinha despertando interesse, por parte do mundo acadêmico, desde a virada dos anos 70 para os 80 , em meio ao declínio do Welfare State nos países desenvolvidos, como podemos observar a partir dos trabalhos de Mauro Cappelletti e Jurgen Habermas.

Cappelletti, em Juízes Legisladores? (1993) já indicava a "Grande Transformação" do papel do direito na sociedade moderna. Essa mudança é percebida pelo fato de que os juízes, a partir de segunda metade do século $\mathrm{XX}$, começaram a superar o formalismo jurídico, e passaram a empregar a hermenêutica e, com isso, possibilitar a interpretação dos 
fatos jurídicos. Ao internalizar a "escolha" como procedimento de sua práxis jurídica, o juiz “[...] não pode mais se ocultar, tão facilmente, detrás da frágil defesa da concepção do direito como norma preestabelecida, clara e objetiva, na qual pode basear sua decisão de forma 'neutra'. É envolvida sua responsabilidade pessoal, moral e política, tanto quanto jurídica, sempre que haja no direito abertura para escolha diversa" (CAPPELLETTI, 1993: p.33).

Com efeito, o Poder Judiciário muda no decorrer do período de ascensão e declínio do Estado de Bem-Estar, tornando-se o "Terceiro Gigante" diante dos demais poderes. De um lado, percebemos um Legislativo marcado por uma intensa fragmentação, sobretudo nas sociedades pluralísticas, nas quais a maior parte dos políticos, eleitos localmente, são vinculados eleitoralmente a certos grupos e categorias. Os valores e prioridades desses políticos são, por isso, muito amiúde valores e prioridades locais, corporativos ou de grupo. De outro, a emergência do gigantismo do Estado interventor, administrativo e burocrático característico do Welfare State. Cappelletti chama a atenção ao fato do perigo dos abusos por parte da burocracia, a ameaça da situação de "tutela" paternalística, quando não da opressão autoritária, sobre os cidadãos por parte do onipresente aparelho administrativo e, por isso, ao mesmo tempo distante, inacessível e não orientado para o seu serviço (CAPPELLETTI: p.44-45).

Cappelletti observa que pelo fato de o "terceiro poder" não poder desconhecer as profundas transformações do mundo real, impôs-se aos juízes um novo desafio. A Justiça constitucional, especialmente na forma do controle judiciário da legitimidade constitucional das leis, constitui um aspecto dessa nova responsabilidade. Como demonstrou a evolução de número crescente de países, no Estado moderno o legislador- gigante não poderia mais, sem gravíssimas consequiências, ser subtraído a controle. E, destaca Cappelletti, um dos aspectos dessas novas responsabilidades foi o crescimento sem precedentes da Justiça administrativa, i.e., do controle judiciário da atividade do executivo e de seus derivados. Assim sendo, o Judiciário, ao elevar-se ao patamar dos outros poderes, torna-se, enfim, o terceiro gigante, capaz de controlar o legislador "mastodonte" e o "leviatanesco" administrador (CAPPELLETTI: p.46-47). 
Habermas, por seu turno, em sua obra Teoria da Ação Comunicativa, na qual antecipava algumas das questões as quais voltaria a tratar em Direito e Democracia: entre a facticidade e validade, enfoca a invasão do mundo vida pela integração sistêmica por intermédio do conceito de juridificação. Por juridificação (Verrechtlichung) entende-se, em termos gerais, a tendência que se observa nas sociedades modernas a um aumento do direito escrito. Nesta tendência podemos distinguir entre a extensão do direito, i.e., a regulação jurídica de novos assuntos sociais regulados até o momento de maneira informal, e o adensamento do direito, o que significa a decomposição de uma lei global em várias matérias particulares, i.e., leis individualizadas de acordo com a matéria jurídica (HABERMAS, 1999: p. 504).

O autor propõe uma seqüência tipológica para a constituição da juridificação: a primeira onda de juridificação conduziu ao Estado burguês que se desenvolveu na Europa Ocidental durante o período do Absolutismo. A segunda levou ao estado de direito que adotou uma forma paradigmática na monarquia alemã do século XIX. A terceira conduziu ao Estado democrático de direito, que se difundiu na Europa e nos EUA como conseqüência da Revolução Francesa. Esta última diz respeito ao Estado social e democrático de direito, cuja institucionalização, no curso do século XX, foi fruto das lutas do movimento operário europeu (HABERMAS: p.504-505). Nessa última onda, Habermas observa que se acentuou a colonização da sociedade pelos subsistemas Economia e Estado, já que se faziam mais complexos em consequiência do crescimento capitalista e penetravam cada vez mais profundamente na reprodução simbólica do mundo vida. O resultado desse processo foi a juridificação das relações informais da sociedade como no âmbito familiar e educacional:

La tendencia a la juridificación de esferas del mundo de la vida informalmente reguladas se impone en un ancho frente, cuanto más reconociblemente quedan sometidos el tiempo libre, la cultura, las vacaciones, el turismo, etc., a las leyes de la economía de mercado y a las definiciones del consumo de masas; cuanto más manifiestamente se acomodan las estructuras de la familia burguesa a los imperativos del sistema ocupacional; cuanto más palpablemente asume la escuela la función de distribuir oportunidades profesionales y existenciales, etc. HABERMAS: p.520). 


\section{Quaestio Iuris}

vol.05, $\mathrm{n}^{\circ}$ 02. ISSN 1516-0351

Como podemos perceber, com a crise de representação do Legislativo e o crescimento da intervenção econômica e regulatória do Executivo, o Judiciário sofreu uma "grande transformação", tornando-se, efetivamente, o "Terceiro Gigante”. Logo, o Judiciário veio a se afirmar como espaço de resolução de conflitos e travando relações - nem sempre harmoniosas - de forças não só com as demais instituições dos poderes republicanos (Legislativo e Executivo), como também com a mídia e o mercado. Desse modo, os atores do Judiciário começam a exercer um papel de destaque na democracia contemporânea na representação dos interesses coletivos e difusos da sociedade.

Essa mudança de papel dos operadores e das instituições jurídicas ultrapassaram os terrenos europeu e norte-americano, e podemos perceber a repercussão desse fenômeno em solo latino-americano. Contudo, deve-se ressaltar a especificidade do crescimento do Judiciário no contexto latino-americano em relação aos países de tradição liberal, já que a história latino-americana foi marcada, ao longo de décadas, por regimes militares que desrespeitavam os direitos humanos e controlavam a arena política e jurídica desses países. Jorge Correa Sutil (2000) destaca que o estabelecimento de sistemas políticos democráticos, ou o retorno à democracia, é o fator que tem provocado a reforma judiciária na América Latina recente, e o modo como esse fenômeno tem contribuído para aumentar a importância do papel do Judiciário sob as novas condições políticas. Em muitos países latino-americanos, a história de suas transições recentes para a democracia tem estado tão emaranhada com a história de como lidaram com as violações passadas dos direitos humanos que é quase impossível falar de uma sem discutir a outra.

A transição argentina pode exemplificar essa situação, pois a restauração de seu sistema democrático quase coincide com o processo público contra os generais que estiveram no poder e foram julgados por suas responsabilidades nas violações aos direitos humanos, processos que foram televisionados integralmente. Os juízes e suas habilidades de fazerem cumprir o estado de direito tornaram-se, assim, um dos principais atores dos novos tempos políticos. De acordo com Sutil, daquele dia em diante, o Judiciário argentino vem se transformando num fórum no qual os cidadãos falam, discutem e legitimam muitas de suas reivindicações políticas (SUTIL, 2000: p.285).

A transformação do Judiciário latino-americano, enquanto espaço público que visa a solucionar os conflitos e distribuir justiça às camadas mais pobres e desorganizadas da

Revista Quaestio Iuris, vol.05, nº1. ISSN 1516-0351 p. 256-285 263 


\section{Quaestio Iuris}

vol.05, $\mathrm{n}^{\circ}$ 02. ISSN 1516-0351

população, deve-se, também, à crise, de um lado, do modelo do Estado de Bem-Estar e do sistema Legislativo/partidário e, de outro, o fortalecimento da economia de mercado. Como ressalta Jorge Correa Sutil:

Uma economia de mercado aberto descentraliza os fóruns de resolução de disputa. Enquanto o governo era o grande investidor nas sociedades latino- americanas, que controlava os preços, os sindicatos e a maioria dos empregos, os partidos políticos e as instituições do Executivo e Legislativo eram os fóruns mais importantes onde se colocavam as expectativas e as soluções dos conflitos entre os grupos sociais. Os conflitos mais importantes que surgem hoje em dia na América Latina normalmente não acabam mais em exigências para o governo mudar o modo como os benefícios sociais são distribuídos. Ao contrário, os agentes privados se confrontam no mercado ou nos tribunais. [...] Durante o século XX na América Latina, os governos, os partidos políticos e várias instituições públicas usaram a linguagem da justiça social e da dignidade humana. Os não-privilegiados aprenderam por mais de 50 anos como se integrar à sociedade e conseguir os benefícios sociais por meio desses canais políticos. Mas hoje esses canais políticos perderam muito de seu peso. O Judiciário, que com certeza não tem sido na tradição latino-americana um fórum importante para os não-privilegiados apresentarem as suas reivindicações, pode tornar-se, finalmente, sob as novas condições, um lugar importante para integrar a justiça social (SUTIL: p. 287 e 295).

Com efeito, a partir da crise de representação política e o desinteresse por parte da população em ingressar e de se mobilizar nos partidos políticos, as representações funcionais jurídicas que não tinham grande destaque no cenário político e social, como o Ministério Público e a Defensoria Pública, tornaram-se, no contexto brasileiro, pós- 1988, atores de relevância (sobretudo o primeiro, em nível nacional) ao assumirem para si, além da defesa dos direitos humanos, os chamados "novos" direitos, como os de proteção ambiental, da posse da terra, do interesse dos consumidores contra o mercado, etc., obtendo, desse modo, uma divulgação significativa de suas ações nos espaços midiáticos.

\section{2) A emergência da representação funcional: crise da representação política?}

Revista Quaestio Iuris, vol.05, nº1. ISSN 1516-0351 p. 256-285 264 
As representações funcionais de direito estatal seguem a tradição republicana iniciada na era Vargas durante os anos 30 na sociedade brasileira. Essa tradição indica que, ao lado da representação política, a representação funcional tem sobrevivido ao longo do tempo, a despeito das mudanças no campo político brasileiro, a exemplo do período liberaldemocrático de 1945/1964, e do regime tecnocrático-militar de 1964/1985. A Constituição de 1988, longe de ter findado a representação funcional, ampliou a sua presença, tendo em destaque as instituições jurídicas como o Ministério Público Federal, sendo este encarregado de defender legalmente os direitos coletivos e difusos da sociedade. Desse modo, as instituições do direito tornaram-se expressivos canais de representação entre a sociedade e o Estado, constituindo, dessa forma, um novo cenário da democracia brasileira. Há, com efeito, uma convivência da cidadania política com a cidadania jurídica. Isso não significa que haja uma substituição do sistema representativo, ou mesmo a condenação da cidadania política, mas sim, a convivência de ambas as cidadanias numa democracia contemporânea, numa sociedade complexa como a brasileira. Ademais, a própria cidadania política tem sofrido intensas modificações nos último dois decênios, como chama a atenção Wanderley Guilherme dos Santos, ao afirmar que os sistemas de representação tradicional, com os partidos políticos, tiveram de dividir seu espaço de representação como os movimentos sociais e as organizações de caráter corporativo (SANTOS, 1986: pp.18-19).

As democracias representativas ocidentais, segundo Paul Hirst, são uma curiosa mistura de sucesso e fracasso. São bem-sucedidas no nível da legitimação da autoridade governamental, mas ao preço de um baixo nível de participação do cidadão e de um baixo nível de efetiva fiscalização do processo de tomada de decisão governamental. Contudo, como observamos ao longo das últimas décadas com a crise de legitimidade das ditaduras políticas/militares, o eleitorado democrático teme qualquer partido ou grupo que defenda algum outro sistema que não a democracia de massa multipartidária. A democracia representativa pode apenas ser suplementada, não suplantada. E só pode ser suplementada de um modo que os grandes partidos possam aceitar e que o eleitorado endosse (HIRST,1993: pp. 12 e 13).

Para Paul Hirst, as formas mais sofisticadas de pluralismo não pretendem abolir a democracia e substituí-la por um sistema novo e único de democracia funcional. O que 


\section{Quaestio Iuris}

vol.05, $\mathrm{n}^{\circ}$ 02. ISSN 1516-0351

pretendem é multiplicar os corpos representativos e complementá-los por formas de representação funcional de interesses sociais organizados, seja diretamente formas corporativas de interesse societal, seja indiretamente pelas instituições der direito estatal. O pluralismo, portanto, dá mais espaço para os meios organizados de influência, que representem categorias específicas de cidadãos, e aumente o campo de interação entre os órgãos públicos e a sociedade civil (HIRST, 1993: p. 15).

Como observa Werneck Viana (2005), esses novos atores do direito de instituições tradicionais (ou novas), como o Ministério Público, os Juizados Especiais e a Defensoria Pública, autoproclamam - se defensores no plano prático legal dos interesses republicanos e também do homem comum da sociedade. Esse argumento refaz o sentido da distinção estabelecida por José Murilo Carvalho (1995) entre cidadão-doutor, cidadão simples e o cidadão-elemento. Ele tem, pelo menos em princípio, nessas instituições os canais que possam representar seus interesses e, o que é mais importante ressaltar aqui, o cidadãodoutor também não se encontra mais impermeável às sanções. Ao contrário das afirmações pessimistas, houve nos últimos anos diversas operações dirigidas pelo Ministério Público, em associação com a Polícia Federal, na prisão de várias pessoas representando o poder público (desembargadores, juízes, procuradores, deputados, prefeitos, etc.), o poder do mercado (banqueiros, empresários, comerciantes, companhias prestadores de serviços, etc.) e mesmo nas ongs ${ }^{4}$.

Werneck Vianna vai ao encontro da afirmação de Poulantzas de que a crise do Welfare State e o avanço do neoliberalismo acabou por resultar tanto numa crise de representação partidária e da própria política, como também no desmonte de seu regime de administração social e na desregulamentação do mundo dos direitos, produzindo uma massa de indivíduos expostos às variações da lógica de mercado, desamparados de qualquer sistema de proteção. No entanto, essa desconstrução do Estado de Bem-Estar não afetou a estrutura judiciária que esse modelo estatal instituíra, e com ela um conjunto de operadores jurídicos imersos numa cultura constituída pelo capitalismo organizado (2008:96). O fortalecimento das representações funcionais como o Ministério Público, a Defensoria Pública e o Judiciário (em especial os Juizados Especiais), é resultado da ação

\footnotetext{
${ }^{4}$ Vide as mega operações Anaconda, Hurricane, Abate Harina,Praga do Egito, Cavalo de Tróia, Medusa, Vampiro,Sanguessuga,Toque de Midas, Narciso,Turko, Gladiador, Satiagraha e Pathos empreendidas em conjunto pelo Ministério Público Federal e a Polícia Federal.
}

Revista Quaestio Iuris, vol.05, no 01. ISSN 1516-0351 p. 256-285 266 
do Legislador de 1988, i.e, da representação política que elaborou a Carta de 1988. Assim sendo, é o legislador quem confirma aos operadores jurídicos do Estado o equivalente funcional do "welfare" (Werneck Vianna, 2008: p.104).

Maria Tereza Sadek - pioneira, ao lado de Werneck Vianna, em pesquisas no campo das Ciências Sociais sobre a judicialização no Brasil - converge em muitos aspectos com essa posição no tocante ao fortalecimento da representação funcional do Ministério Público a partir de 1988, e o papel de destaque que vem obtendo no cenário político brasileiro. De fato, a sua atual estrutura organizacional, como a sua autonomia, não tinha precedente na história de nossa formação social, e tampouco um modelo similar internacional, pelo menos que anteceda a 1988. Tanto Sadek como Werneck Vianna ressaltam o novo papel que o MP tem exercido, já que deixou de ser advogado dos interesses do Estado para converte-se em defensor da sociedade $^{5}$ (WERNECK VIANNA, 2008: p.101; SADEK, 2008: p.112). É o exemplo das ações do MP em relação à administração pública direta no que se refere ao controle das ações dos agentes públicos e das políticas públicas programadas pelo aparelho estatal, na qual recorrem à lei de responsabilidade fiscal e, desse modo, incorporando o controle da administração pública ao sistema de proteção dos interesses difusos e coletivos (WERNECK VIANNA 2008: p.104). Como afirma Sadek, a nova identidade e as novas atribuições designadas ao MP impuseram um novo perfil à instituição, tornando-a uma agência fundamental no controle de atos e ações de outros atores estatais, entidades governamentais e organizações sociais, bem como uma instituição defensora dos interesses e direitos constitucionais do cidadão e da sociedade (SADEK, 2008: p.115). Esse aspecto singular do MP no cenário político brasileiro em sua ação sobre as demais instituições públicas, o caracterizam enquanto um agente de accountability ${ }^{6}$, concorrendo diretamente com outras representações funcionais

\footnotetext{
${ }^{5}$ Embora sejam definidos como "defensores" da sociedade, esses operadores se reconhecem como agentes do Estado. Segundo um defensor público "É importante ressaltar que a presença do Defensor traz para o presídio a presença estatal. O Defensor lá dentro representa o Estado não só na condição jurídica de atender, mas também uma função extra de fiscalização da unidade para ver os direitos do preso, as condições de alojamento, trabalhando ao lado das direções das unidades e do DESIPE (MOTTA, 2009: p. 77)".

${ }^{6}$ Por accountability entende-se como seu significado a responsabilidade (ou responsabilização) do agente estatal em relação ao dinheiro público(ou gastos orçamentários). Em artigo publicado pela Revista de Administração Pública(RAP) $\mathrm{n}^{\circ}$ 24, vol. 2, 1990, “Accountability: quando poderemos traduzi-la para o português?", Ana Maria Campos aponta as impossibilidades de se traduzir esse conceito à realidade brasileira ao afirmar que inexiste, de um lado, esse sentido que o conceito evoca na dogmática do direito administrativo, e, de outro, ainda mais importante, a ausência de uma cultura republicana e transparente por parte dos agentes
} 


\section{Quaestio Iuris}

vol.05, $\mathrm{n}^{\circ} 02$. ISSN 1516-0351

estatais que têm como princípio normativo a avaliação e controle com base na lei de responsabilidade fiscal, notadamente os Tribunais de Contas.

A forma de atuação desses agentes públicos estatais provoca uma nova leitura do conceito de Estado embora ainda não seja empregada pela maioria dos pesquisadores nocampo do Direito, ou mesmo da Ciência Política (em especial pelo enfoque das teorias sistêmicas, ou neo-institucionalistas e mesmo no marxismo ortodoxo) ${ }^{7}$. No campo jurídico ainda prevalece a análise de Hans Kelsen (1990), que conceitua o Estado como uma pirâmide normativa, fechado, impermeável a sociedade, opaco em si, sem fissuras e contradições internas. Ao contrário, as ações do Ministério Público, como as da Defensoria Pública e da Magistratura, incluindo também a Polícia Federal, os Tribunais de Contas e as Agências Reguladoras conduzem a um outro olhar sobre o Estado, mais próximo da definição de Nicos Poulantzas (1978) cuja definição do conceito de Estado é baseada numa perspectiva relacional, i.e., o Estado é definido como uma arena de conflitos entre as classes e os grupos sociais, e permeado de fissuras e contradições. O Estado, portanto, não pode ser entendido como algo homogêneo, redutível a sua normatividade porque, distintamente, há nele uma heterogeneidade de elementos na medida em que é formado por um conjunto de instituições diferenciadas no campo de suas ações. Deve-se ressaltar que o

públicos na esfera administrativa burocrática. Essa posição tem sido contestada em artigos mais recentes. Veja principalmente Guillermo O'Donnell, "Accountability Horizontal”, Revista de Estudios sobre el Estado y la Sociedad, No 4, pp.161-188, 1998 e o trabalho de José Antonio Gomes do Pinho e Ana Rita Silva Sacramento Accountability: Já podemos Traduzi-lo para o Português?, apresentado no EnAPG/ANPAD, 2008.

${ }^{7}$ Nas pesquisas sobre o fenômeno da judicialização, no campo da Sociologia e na Ciência Política, tem predominado a perspectiva neo-institucionalista em suas distintas correntes como a histórica, a sociológica e a escolha racional como pode-se perceber em diversos trabalhados pulicados em revistas e anais de congressos como Ernani Carvalho e Vanessa Elias Oliveira Judicialização da política: um tema em aberto, XXVI Encontro da Associação Nacional de Pós-Graduação em Ciências Sociais, 2002, Caxambú; Vanessa Elias Oliveira Judiciário e privatizações: existe uma judicialização da política?, Dados, vol. 48, $\mathrm{n}^{\circ}$ 3, 2005; Matthew M. Taylor, O judiciário e as políticas públicas no Brasil, Dados, vol. 50, n², 2007; Ernani Carvalho, Revisão judicial e judicialização da política no direito ocidental: aspectos relevantes de sua gênese $e$ desenvolvimento, Revista de Sociologia e Política, no28, 2007; Fábio Kerche, Autonomia e discricionariedade do Ministério Público no Brasil, Dados, vol. 50, n², 2007; Vitor Ferraz Jr. e Rafael Cortez, Em busca da judicialização perdida: o TSE e o problema da accountability, XXXI Encontro da Associação Nacional de Pós-Graduação em Ciências Sociais; Alexandre Veronese, A judicialização da política na América Latina: panorama no debate teórico contemporâneo, VI Encontro da ABCP, 2008; Christiane Jalles de Paula, Ministério Público e accountability: investigação criminal e controle externo da polícia no Rio de Janeiro, VI Encontro da ABCP, 2008; Cássio Casagrande, Ministério Público e a Judicialização da Política, Sergio Antonio Fabris Editor, 2008. Numa posição distinta do neoinstitucionalismo, é a perspectiva sistêmica empregada no trabalho de Marcelo Pereira de Mello e Delton Soares Meirelles A "Cultura Legal" do cidadão de Niterói. Cadernos CEDES, Rio de Janeiro, n. 3, 2006.

Revista Quaestio Iuris, vol.05, n01. ISSN 1516-0351 p. 256-285 268 


\section{Quaestio Iuris}

vol.05, $\mathrm{n}^{\circ}$ 02. ISSN 1516-0351

Estado sendo definido como uma arena de conflitos, não significa que as lutas só se travam entre as diferentes instituições, mas também internamente às mesmas. Isto significa afirmar que os conflitos não se reduzem apenas aos estabelecidos entre os distintos poderes (o judiciário, o legislativo e o executivo), ou entre os ministérios, secretarias, agências reguladoras, autarquias e tribunais, de modo concorrente - mas se dão, sobretudo, nas estruturas internas a cada instituição e entre seus respectivos agentes.

Outro aspecto relacionado ao Estado contemporâneo, destacado por Poulantzas, é que este incorpora também em seu espaço interno as demandas dos setores subalternos da sociedade. O Estado concentra não apenas a relação de forças entre frações do bloco no poder, mas também a relação de forças entre estas e o pólo dominado da sociedade (POULANTZAS, 1978: p.155). É impossível compreender as organizações e funções do Estado sem incluir seu papel de mediador do conflito entre os grupos dominantes e os dominados. $\mathrm{O}$ alargamento dos direitos em direção às classes e aos grupos dominados dá-se também dentro das instituições estatais, devido à inserção e à influência que podem exercer no interior delas. Se as lutas políticas ocorridas no Estado atravessam suas instituições, é porque essas lutas estão desde já inscritas na trama do Estado do qual elas esboçam a configuração estratégica: “(...) é o Estado que está imerso nas lutas que o submergem constantemente. Fica entendido no entanto que até as lutas (e não apenas as de classe) que extrapolam o Estado não estão no entanto fora do poder, mas sempre inscritas nos aparelhos de poder que as materializam e que, também eles, condensam uma relação de forças" (POULANTZAS, 1978: p.154).

Poulantzas também ressalta que as contradições e os conflitos sociais se inscrevem no seio do Estado por meio também das divisões internas no seio do pessoal de Estado em amplo sentido (administração, judiciário, militares, policiais, etc.). Mesmo se esse pessoal constitui uma categoria social detentora de uma unidade própria, efeito da organização do Estado e de sua autonomia relativa, ele não deixa de ter um lugar no conflito social, e é, então, dividido. Se as contradições dos setores dominantes se refletem nos agentes de Estado, as pressões dos setores populares, e suas contradições, também os atingem já que se encontram presentes na ossatura do Estado moderno. Decerto que o Estado reproduz e inculca uma ideologia de neutralidade, de representar uma vontade e interesses gerais, de árbitro dos conflitos sociais. É a forma que reveste a ideologia dominante no seio das 


\section{Quaestio Iuris}

vol.05, $\mathrm{n}^{\circ}$ 02. ISSN 1516-0351

instituições estatais: mas esta ideologia não domina inteiramente, pois os subconjuntos ideológicos dos setores dominados estão também cristalizados sob a dominância desta ideologia, nas instituições do Estado.

Contudo, isso não significa que os agentes do Estado identificados com as demandas das classes populares adotem uma postura radical nas suas práticas no interior do Estado. Para Poulantzas, os agentes de Estado que pendem para as massas populares vivem comumente suas revoltas nos termos da ideologia dominante, tal como ela se corporifica na ossatura do Estado. O que quase sempre os coloca contra os setores dominantes e as esferas superiores do Estado, é que a dominação de grandes interesses econômicos sobre o Estado põe em questão seu papel de garantia da "ordem" e da "eficácia" socioeconômica, destrói a "autoridade" estatal e o sentido das tradicionais hierarquias no seio do Estado. Eles interpretam o aspecto, por exemplo, de uma democratização do Estado não como uma intervenção popular nos negócios públicos, mas como uma restauração de seu próprio papel de árbitros acima dos conflitos sociais. Eles reivindicam uma "descolonização" do Estado em relação aos grandes interesses econômicos, significando que o Estado assuma seu próprio papel político. Assim, mesmo os agentes estatais inclinados para as massas populares, não apenas não tratam da questão da reprodução da divisão social do trabalho no interior do Estado - a burocratização hierarquizada -, mas, além disso, geralmente não dão importância à divisão política dirigentes-dirigidos enraizada nas instituições estatais (POULANTZAS, 1978: pp.170-174).

O Ministério Público Federal ilustra bem essa perspectiva relacional do Estado - no que se refere aos limites legais apontados por Poulantzas - haja vista as múltiplas ações que vem desempenhadas nos últimos anos em termos de absorção das demandas da sociedade, ou representando os interesses da sociedade civil, seja ela organizada ou não. Suas ações estendem-se a diversos campos como a improbidade administrativa, na defesa do meio ambiente, nos direitos humanos, na área do consumidor, ou seja, o leque é muito amplo em termos de representação. Talvez há vinte anos, se falássemos de danos ambientais, ou a questões vinculadas ao preconceito racial ou de gênero, talvez o cidadão consciente de seus direitos viesse a procurar os partidos políticos como canal de representação da defesa de seus interesses. Hoje, em geral, além das representações funcionais estatais como o Ministério Público, a Magistratura ou a Defensoria Pública, o cidadão individual, e mesmo 


\section{Quaestio Iuris}

vol.05, $\mathrm{n}^{\circ}$ 02. ISSN 1516-0351

coletivo, tem demandado pelos novos movimentos sociais, as chamadas ONGS, (organizações não governamentais) que também são representações funcionais de caráter societal, a defesa de seus direitos. Outro aspecto singular do MP no cenário político brasileiro é a sua ação nas demais instituições públicas, sobretudo as que se encontram no Poder Executivo, atuando enquanto um agente de accountability, sobretudo no que concerne aos aspectos relativos à Lei de Responsabilidade Fiscal e na improbidade administrativa, concorrendo diretamente com outras representações funcionais estatais que têm como característica avaliação e controle, notadamente os Tribunais de Contas.

\section{3) Limites da judicialização e da representação funcional}

Evidentemente que o fenômeno da judicialização não é desprovido de críticas, tanto no aspecto conceitual, como também no que concerne a seus efeitos políticos. Em relação à sua imprecisão epistêmica, Maciel e Koerner (2002) apontam diversos e conflitantes significados que esse conceito evoca, ora uma leitura positiva dele significando um avanço democrático na sociedade, ora uma posição negativa que representa na sociedade devido a sua posição contramajoritária e oposta à soberania popular. Ademais, os seus diferentes significados são apropriados em distintos campos do conhecimento - sociologia, ciência política, direito - o que amplia ainda mais a sua confusão epistemológica. Essas múltiplas interpretações sobre o fenômeno da judicialização são inclusive apontadas por Tate e Vallinder em seu livro pioneiro a essa problemática.

Tate e Vallinder (1995: p. 5) chamam a atenção para as diversas interpretações positivas e negativas desse fenômeno. No sentido mais geral, pode-se definir o conceito de judicialização como, de um lado, a expansão do direito e o fortalecimento das instituições de Justiça, e, do outro, a inserção dos agentes jurídicos na esfera política e no mundo vida (no nosso país, seria o caso dos magistrados, procuradores da república e de justiça e defensores públicos) positivamente ou negativamente, de acordo com a perspectiva teórica e política do pesquisador. Aliás, essa polissemia não é uma característica exclusiva desse conceito, mas também de outros no campo das ciências sociais que têm marcado uma 


\section{Quaestio Iuris}

vol.05, $\mathrm{n}^{\circ}$ 02. ISSN 1516-0351

intensa polêmica nesse campo, a exemplo do conceito de trabalho, classes sociais, poder, entre outros. $^{8}$

Sobre os efeitos políticos da judicialização, um dos seus mais destacados críticos tem sido Antoine Garapon, intelectual e juiz francês. Garapon percebe que o crescimento do Judiciário como ator político deve-se à crise de representação política e da própria democracia moderna, na medida em que ocorre um enfraquecimento dos poderes Legislativo e Executivo. Garapon reconhece na Justiça o "último refúgio de um ideal democrático desencantado" (1999: p.26). O sucesso da Justiça é inversamente proporcional ao descrédito que afeta as instituições políticas clássicas, causadas pela crise de desinteresse e perda do espírito público. Portanto, “(...) a cooperação entre os diferentes atores da democracia não é mais assegurada pelo Estado, mas pelo direito, que se coloca, assim, como a nova linguagem política na qual são formuladas as reivindicações políticas. A justiça tornou-se um espaço de exigibilidade da democracia. Ela oferece potencialmente a todos os cidadãos a capacidade de interpelar seus governantes, de tomá-los ao pé da letra e de intimá-los a respeitarem as promessas contidas na lei”. (GARAPON, 1999: pp.48-49)

Para Garapon, esse crescimento do poder da Justiça esconde dois fenômenos aparentemente distintos, cujos efeitos convergem e se reforçam: de um lado, o enfraquecimento do Estado, sob pressão do mercado; e, de outro, o desmoronamento simbólico do homem e da sociedade democráticos. O enfraquecimento do Estado é uma conseqüência direta da "globalização" da economia. Desse modo, o mercado, ao mesmo tempo em que despreza o poder tutelar do Estado, multiplica a recorrência ao jurídico.

De acordo com Garapon, “(...) o juiz surge como um recurso contra a implosão das sociedades democráticas que não conseguem administrar de outra forma a complexidade e a diversificação que elas mesmas geraram. O sujeito, privado das referências que lhe dão uma identidade e que estruturam sua personalidade, procura no contato com a justiça uma

\footnotetext{
${ }^{8}$ No campo das Ciências Sociais há uma pluralidade de paradigmas, o que as diferenciam das Ciências Naturais, já que estas possuem paradigmas mais coesos, embora isso não signifique que não haja mudanças ou conflitos relativos a interpretações de determinados fenômenos. Nas Ciências Sociais, vários conceitos, como o de ideologia, possuem diferentes sentidos. Se verificarmos de Destut de Tracy a Althusser, passando por Marx, Lukács, Mannheim, Gramsci, entre outros, estaremos falando da mesma palavra, mas sem a mesma acepção conceitual. O mesmo se dá com o conceito de Estado. O que há de semelhante nesse conceito em Weber, Kelsen, ou Poulantzas?. Na mesma situação encontra-se o conceito de simbólico, já que Lévi-Srauss, Gertz e Bourdieu tratam de modo distinto e divergente a mesma palavra.
} 


\section{Quaestio Iuris}

vol.05, $\mathrm{n}^{\circ}$ 02. ISSN 1516-0351

muralha contra o desabamento interior. Em face da decomposição do político, é então ao juiz que se recorre para a salvação.” (GARAPON, 1999:26-27)

Andréas Kalyvas (2002) vai ao encontro das posições de Garapon e as radicaliza ainda mais quando aponta uma tendência autoritária do liberalismo legal em detrimento da soberania popular. Conforme afirma Kalyvas, há uma gradual transferência do poder político do Executivo e do Legislativo para o Judiciário e uma concentração de poder deste último. Aspectos-chave de questões socialmente importante não são mais estabelecidas pelo voto legislativo, mas decididas por juízes não eleitos da Corte Suprema. Essa tendência contramajoritária, que se tornou um modelo praticado nos EUA, é agora exportada e reproduzida em diversos países da Europa Ocidental e em muitos países das novas democracias da Europa Central e do Leste.

Essa vertente aponta para uma larga mudança estrutural em direção à despolitização e neutralização da legitimidade democrática e privação da soberania popular de sua responsabilidade política. Segundo Kalyvas, não é surpreendente que a deliberação da Corte Suprema, na qual se decidiu o resultado das eleições presidenciais dos EUA em 2000, tenha sido elevada ao status de um modelo ideal para a política consensual das sociedades liberais. Ademais, a apropriação gradual, pelo Judiciário, do poder de tomar decisões políticas, e a proliferação de Cortes constitucionais dotadas de poder de revisão judicial sobre a legislação, tem criado uma grande confusão a exemplo de não saber onde reside a autoridade política suprema. Contrariamente à subordinação prévia dos demais poderes ao Executivo, atualmente eles têm tomado, antes, uma forma ambígua e elusiva que os impossibilita de situá-los e determiná-los numa instância institucional específica.

Se no final dos anos 1970 Poulantzas afirmava a emergência de um estatismo autoritário, no qual o poder executivo preponderava sobre os demais poderes, e fortalecia o aparato repressivo de Estado, não se restringindo as ditaduras militares da América Latina ou da África, mas também presente nos Estados "democráticos liberais" (POULANTZAS, 1978), a exemplo dos governos Thatcher e Reagan. Para Kalyvas vivemos hoje uma nova forma de Estado na qual ele denomina de legalismo liberal autoritário. O legalismo liberal autoritário caracteriza-se pela gradual transferência de poder do executivo e do legislativo para o judiciário e concentração de poder por este último, particularmente as tomadas de decisão dos juízes em tribunais de instância superior. Isso significa para Kalyvas a 


\section{Quaestio Iuris}

vol.05, $n^{\circ} 02$. ISSN $1516-0351$

formação de uma tendência contramajoritária ${ }^{9}$, que caminha em direção a despolitização e a neutralização da legitimidade democrática e a privação da soberania popular de sua responsabilidade.

Para Kalyvas, de um ponto de vista histórico, nós estamos testemunhando um surpreendente ressurgimento e uma revigoração do domínio da lei e da legalidade liberal formal. Essa restauração inesperada da legalidade formal, na forma do modelo de democracia procedural, que tem sido adotado pelas principais correntes do pensamento contemporâneo, claramente ameaça esvaziar, enfraquecer e neutralizar o princípio da soberania popular ao reduzi-la a um mero "fato de pluralidade" e a competição institucionalizada entre as elites dominantes. Segundo esse autor, neste contexto em que há uma tendência em regular tudo por meio de regras, procedimentos e normas instituídas, tornaram a política confinada aos limites constitucionais impostos pela legalidade dominante. A tentativa de impeachment ao Presidente Clinton é um caso exemplar de como o discurso da lei pode ser usado para minar um político do Poder Executivo popularmente eleito. Seguindo estritamente os procedimentos legais prescritos, o Partido Republicano foi capaz de transformar os vícios privados em crimes públicos, a fim de subverter o princípio da legitimidade popular ${ }^{10}$.

Kalyvas destaca que o mais interessante e revelador, neste caso, é que o processo inteiro, o qual poderia muito bem ter revertido o resultado de uma eleição democrática, recordando um golpe legal, foi realizado sem nenhuma violação da Constituição ou quebra da lei. Ao contrário, seu sucesso foi firmado numa aplicação precisa e correta do sistema legal estabelecido, demonstrando que quando é usado corretamente e consistentemente, o governo da lei pode voltar à legalidade contra a legitimidade democrática, o constitucionalismo liberal contra a soberania popular, a norma abstrata contra a vontade, a lei contra sua fonte simbólica instituinte: o povo (KALYVAS, 2002: pp.123-127).

\footnotetext{
${ }^{9}$ Numa entrevista dada ao Consultor Jurídico (CONJUR) em 08/03/2006, o ex-ministro do STF Sepúlveda Pertence afirma que "os governos reclamam (estão no papel deles), jogam obviamente com a lógica de resultado. Todo governo tem que ter um programa e quer crer que vai salvar o país com ele. Não é da lógica do governante preocupar-se com uma 'regrinha' aqui, com um princípio ali. A nossa lógica é outra. O nosso papel é contramajoritário."

${ }^{10}$ Exemplo de intervenção do poder judiciário sobre a legitimidade política da escolha de dirigentes políticos em nível de governo estadual foi a cassação dos mandatos dos governadores Cássio Cunha Lima da Paraíba, Jackson Lago do Maranhão e de Marcelo Miranda do Tocantins.
} 
Contrariamente à concepção liberal do "Império da Lei" ser antitética ao autoritarismo estatal, Kalyvas percebe nela uma intensificação da violência do Estado, embora distinta daquela empregada pelo autoritarismo estatal do século passado. A seu ver, a principal função do domínio da lei e da legalidade não é conceber a violência estatal como era empregada anteriormente, mas, antes, fornecer a semântica, a norma e a estrutura institucional necessária para seu pleno exercício e expressão. Nas sociedades capitalistaliberais contemporâneas, a opressão estatal não está localizada abaixo, próxima, ou contra a lei. Não se esconde atrás de um "véu da ignorância", nem representa um momento extralegal ou excepcional da hegemonia burguesa. Existe principalmente por meio, e dentro da lei. A violência está plenamente de acordo com a lei para que ela seja organizada e mobilizada de modo completamente visível e público. A violência do governo da lei representa a situação normal do Estado capitalista-liberal e não a sua exceção (KALYVAS, 2002: p.128).

Outro aspecto problemático a ser ressaltado é que as instituições de representações funcionais do direito não são impermeáveis à famosa "lei de ferro da oligarquia" de Robert Michels (1982). Como qualquer organização, a exemplo dos partidos políticos, ou das igrejas, essas instituições podem vir a se burocratizarem (na acepção negativa do termo) e se afastarem dos princípios republicanos que as norteiam. Como observa Michels, "A organização deixa assim, de ser um meio, para tornar-se um fim. (...) Quem diz organização diz oligarquia" (1982: pp.223 e 238) ${ }^{11}$. As organizações partidárias democráticas são, para Michels, objeto de uma curiosa contradição: lutam em princípio contra a oligarquia do poder, pela instauração de autêntica democracia. Mas a sua própria organização interna não é democrática. Essa oligarquização das instituições estatais do direito difere-se das partidárias (que é a referência de Michels) devido que a sua relação de poder oligárquico não se trava internamente às mesmas, pois há um baixo nivelamento hierárquico entre esses agentes, mas deles por meio de sua organização sobre a sociedade civil e as representações

\footnotetext{
${ }^{11}$ Michels embora seja associado à escola elitista italiana, a sua análise sobre o poder da burocracia e da "lei de bronze da oligarquia" tem sido apropriada (ainda que criticamente) por autores de esquerda: no campo marxista veja os elogios à obra de Michels por Nikolai Bukharin em Tratado do Materialismo Histórico, Lisboa, Ed. Centro do Livro Brasileiro, s/d; veja também o conceito de burocratismo de Nicos Poulantzas em Poder Político e Classes Sociais, São Paulo, Ed. Martins Fontes, 1977 e o livro de Henri Weber Marxismo e Consciência de Classe, Lisboa, Moraes Editores, 1977; não pertencendo à corrente marxista, a principal referência é Claude Lefort Éléments d'une critique de la bureaucratie, Paris, Droz, 1971.
} 


\section{Quaestio Iuris}

vol.05, $\mathrm{n}^{\circ}$ 02. ISSN 1516-0351

políticas. Essa burocratização das organizações e de seus agentes expressam o que Poulantzas denomina de burocratismo, expressando a ideologia dominante do conjunto da formação capitalista. Em outra palavras, o burocratismo representa uma organização hierárquica, por delegação de poderes, do aparelho de Estado que tem efeitos particulares sobre o seu funcionamento, como o monopólio burocrático do saber em relação a ausência de saber das massas (POULANTZAS, 1977: pp. 344-345).

Embora Sadek destaque o baixo nível hierárquico entre os procuradores do MP devido a ampla discricionaridade que possuem (2008: 117), não significa haver uma rígida relação de poder assimétrica dos procuradores sobre o corpo de funcionários do MP. O tratamento de "doutor" é comum enre os procuradores, como também no tratamento que lhes confere os funcionários de outras carreiras do MP. Mesmo aqueles que exercem funções de conhecimento específico, a exemplo dos antropólogos do MPF, não são tratados de forma isonômica pois não são reconhecidos como "doutores".

O corporativismno também é um aspecto que separa as instituições estatais do direito em relação aos princípios republicanos. Um exemplo recente dessa dissociação entre os interesses corporativos das instituições estatais do direito e da sociedade civil foi quando o Conselho Nacional de Justiça e Conselho Nacional do Ministério Público votaram em causa própria pelo aumento salarial dos magistrados e dos procuradores de justiça. ${ }^{12}$ Outros problemas como a insistência do nepotismo nos Tribunais de Justiça (indo de encontro a Resolução $\mathrm{n}^{\circ} 7$ de 2005 do CNJ), além do foro privilegiado, estabelecem a formação de "castas superiores" contrariando o princípio republicano de isonomia entre os cidadãos diante as instituições públicas e a Justiça Esse é um problema que vem se constituindo nas instituições estatais do direito em relação aos novos pares que estão sendo incorporados por meio dos concursos públicos, e muitos deles visando mais uma busca de um emprego estável, e que lhes concede um "status quo" diante o cidadão "comum", do que um firme compromisso com a expansão e afirmação dos direitos dos cidadãos, principalmente

\footnotetext{
${ }^{12}$ Esses fatos foram noticiados pela mídia em novembro de 2006.

${ }^{11}$ Vide as denúncias do CNJ de práticas de nepotismo nos Tribunais de Justiça do Rio de Janeiro (2006), Piauí (2009), Paraíba (2009), Rio Grande do Sul (2009). Mais recentemente nos dias 2602;2010 e 01032010, o jornal $O$ Globo publicou as denúncias do CNMP e do CNJ sobre os casos de improbidade administrativa do MP do Piauí e do TJ da Bahia, respectivamente.
}

Revista Quaestio Iuris, vol.05, no01. ISSN 1516-0351 p. 256-285 276 


\section{Quaestio Iuris}

vol.05, $\mathrm{n}^{\circ}$ 02. ISSN 1516-0351

quando se perde a referência por essas novas gerações o passado recente de nosso país marcado pelo autoritarismo e a violência estatal ${ }^{13}$.

Essa preocupação de uma "oligarquização" das instituições de direito estatal tem sido alvo de reflexão por outros analistas do fenômeno da judicialização, embora não citem diretamente a teoria de Michels como fonte de inspiração. A pesquisa de Rogério Arantes (2000) sobre o Ministério Público tem sido a principal referência crítica à judicialização política no Brasil devido a visão tutelar que esta instituição tem sobre a sociedade brasileira.

De acordo com Rogério Arantes, a história do Ministério Público brasileiro é uma história de sucesso, pois em menos de vinte anos a instituição conseguiu passar de mero apêndice do Poder Executivo para a condição de órgão independente. Nesse processo que alterou sua estrutura, funções e privilégios, o Ministério Público também abandonou seu papel de advogado dos interesses do Estado para arvorar-se a defensor público da sociedade. Para Arantes, o voluntarismo político dos integrantes do Ministério Público em sua pretensão de se transformarem em agentes políticos responsáveis pela defesa da cidadania, talvez seja o mais relevante aspecto do processo de judicialização da política e da politização da Justiça no Brasil. A noção de voluntarismo político demarca o condicionante endógeno desse processo de transformação do Ministério Público.

Em sua análise sobre o voluntarismo do Ministério Público, Arantes destaca que os promotores reproduzem uma concepção de mundo na qual vêem a sociedade como "hipossuficiente", i.e., incapaz de se defender diante dos poderes do Estado e do mercado. Verificou-se, num survey aplicado no Ministério Público, que nada menos de $84 \%$ dos entrevistados concordaram total ou parcialmente com a afirmação de que a "sociedade brasileira é hipossuficiente, isto é, incapaz de defender autonomamente os seus interesses e direitos, e que, por isso, as instituições da Justiça devem atuar afirmativamente para protegê-la". A idéia, em suma, é que temos uma sociedade civil fraca, desorganizada e incapaz de defender seus direitos fundamentais. Além disso, frequientemente, é o próprio Poder Público quem mais desrespeita esses mesmos direitos. Dessa equação resulta a proposta, de natureza instrumental, de que "alguém" deve interferir na relação Estado sociedade em defesa desta última. Instrumental no sentido de que não é para sempre: pelo 


\section{Quaestio Iuris}

vol.05, $\mathrm{n}^{\circ}$ 02. ISSN 1516-0351

menos no momento imediato, "alguém" tem que tutelar os direitos fundamentais do cidadão até que ele mesmo, conscientizado pelo exemplo da ação de seu protetor, desenvolva autonomamente a defesa de seus interesses (ARANTES, 2000:103-104) ${ }^{14}$.

Já Cátia Aída Silva, em sua pesquisa sobre o MP de São Paulo, também percebe como Arantes que os promotores de justiça têm uma visão tutelar da sociedade civil brasileira. Em sua pesquisa qualitativa realizou entrevistas com 21 promotores e demarcou uma distinção entre dois grupos que atuam no Ministério Público de São Paulo. De um lado, o "promotor de gabinete", que embora utilize procedimentos extrajudiciais no exercício de suas funções, dá tanta ou mais ênfase à proposição de medidas judiciais e ao exame e parecer dos processos judiciais dos quais está encarregado. Já o "promotor de fatos", não obstante proponha medidas judiciais e realize atividades burocráticas ligadas às suas áreas, dá tanta ou mais importância ao uso de procedimentos extrajudiciais, mobilizando recursos da comunidade, acionando organismos governamentais e não governamentais, e agindo como articulador político.

Na parte em que analisa a visão dos promotores sobre o poder público e a sociedade, Aída Silva percebe, na fala dos promotores, uma concepção de fragilidade da sociedade civil perante o poder público, daí a necessidade de o Ministério Público intervir em defesa da legalidade. Essas novas atribuições do Ministério Público são vistas pelos entrevistados

\footnotetext{
${ }^{14}$ Em resenha sobre o trabalho de Arantes, Maciel e Koerner (2002, pp.:121 e 122) apontam limitações interpretativas do autor derivadas de equívocos metodológicos aplicados à pesquisa. Como observam os articulistas: "Uma primeira interpretação controversa é relativa às afirmações dos membros do MP quanto a hipossuficiência da sociedade civil, tomadas por Arantes como sinal inequívoco da concepção tutelar (logo, autoritária e paternalista) da instituição. Os conceitos de hipossuficiência, assim como o de tutela, têm dimensão jurídica - é provável que os integrantes do MP os tenham interpretado nesse sentido em suas respostas - e, por isso, parece-nos no mínimo apressado dar-lhes um conteúdo político-ideológico imediato. O mesmo ocorre com as concepções de promotores e procuradores do seu papel pedagógico e ativo na promoção dos direitos coletivos. Tais afirmações constituem não matéria de opinião mas remetem ao próprio desenho institucional do MP e à função profissional dos seus membros. Trata-se de atribuições e objetivos da organização que, legitimados pela Constituição e reafirmados em diversos diplomas legais, mais traduzem o significado atribuído às instituições judiciais nas democracias contemporâneas do que expressam ideologias estritamente corporativas dos seus membros.

Dessa ótica, caberia perguntar se as organizações de justiça seriam, de fato, tão impermeáveis e autônomas em relação às expectativas, interesses e orientações morais, presentes no ambiente sociocultural mais amplo. Conforme tivemos oportunidade de mostrar em pesquisa sobre a atuação do Ministério Público em conflitos ambientais (MACIEL, 2001), o movimento ambientalista emergente no contexto da transição democrática encontrou em lideranças institucionais fortes aliadas para a inserção das suas demandas na agenda política brasileira. A permeabilidade e abertura da instituição a valores do ambiente externo acabaram por conferir-lhe crescente visibilidade pública e legitimação social à sua intervenção nas disputas de natureza coletiva e difusa."
}

Revista Quaestio Iuris, vol.05, $\mathrm{n}^{\circ} 01$. ISSN 1516-0351 p. 256-285 278 


\section{Quaestio Iuris}

vol.05, $\mathrm{n}^{\circ}$ 02. ISSN 1516-0351

como "conquistas da sociedade". Para os entrevistados: a) os poderes e órgãos públicos teriam perdido a "legitimidade" perante a população, pois além dos problemas de corrupção, não estariam mais atendendo às necessidades do cidadão; b) os cidadãos - "a sociedade brasileira" - não seriam capazes de reagir aos abusos e negligência dos poderes públicos, dada a desigualdade socioeconômica e despreparo das associações civis. Assim, o Ministério Público teria vindo "preencher um vácuo" na defesa da "sociedade".

Para os promotores, a "sociedade brasileira" é "desorganizada", "frágil" e composta por cidadãos que "não têm consciência de seus direitos". Dentre os promotores de gabinete aparecem as imagens mais desfavoráveis quanto ao grau de organização da "nossa sociedade", contrapostas à imagem dos países desenvolvidos. Entre os promotores de fato, considera-se que o Brasil mudou e que os cidadãos têm "mais consciência de seus direitos". Mas, ainda assim, a avaliação é de que a "sociedade civil" não alcançou "um nível maior" de organização, e que, por isso, a defesa dos interesses metaindividuais deve ser exercida pelos promotores. Aída percebe que no discurso dos promotores o significado do conceito de sociedade civil muda conforme a circunstância: na Constituinte, a "sociedade" foi capaz de lutar pelos direitos sociais e de apoiar o crescimento do Ministério Público; hoje, a "sociedade" precisa contar com a tutela do Ministério Público para que seus interesses e direitos sejam respeitados; face à ameaça da revisão constitucional e de mudanças nas atribuições dos promotores, é esperado que "a sociedade" se pronuncie a favor do Ministério Público (SILVA, 2001: p. 104-106).

De fato, as instituições estatais do direito não tem a priori uma posição progressista ou conservadora, pois pelo pomnto de vista relacional o que determina efetivamente são as correlações de forças internas às instituições. Exemplo paradigmático de uma posição conservadora do Ministério Público Federal foi a ação direta de inconstitucionalidade impetrada em 2005 pelo ex-Procurador Geral da República, Cláudio Fonteles, sobre a Lei de Biossegurança no trato às pesquisas de células tronco. A atitude do Procurador era nitidamente favorável à posição crítica da Igreja Católica às pesquisas de células tronco, o que confrontava explicitamente ao princípio basilar da separação dos interesses do Estado republicano diante as instituições religiosas ${ }^{15}$. A postura de Fonteles, no entanto, não foi

\footnotetext{
${ }^{15}$ Outra posição conservadora como a de Fonteles foi a do jurista Ives Gandra. Veja a sua entrevista na Terra Magazine no dia 5/03/2008, http://terramagazine.terra.com.br/interna/0,,OI2657289-EI6578,00.html
} 


\section{Quaestio Iuris}

vol.05, $\mathrm{n}^{\circ}$ 02. ISSN 1516-0351

consensual no MPF haja vista o manifesto crítico da Associação Nacional de Membros do Ministério Público de Defesa dos Direitos dos Idosos e Pessoas com Deficiência - AMPID.

A postura conservadora do MPF diante ás pesquisas sobre as células tronco, não significou efetivamente um retrocesso da instituição. Com efeito, não há um movimento pendular que leve uma oscilação do MPF em adotar posições ora progressistas, ora conservadoras, mas sim simultaneidades, ou sincronicidades, em face às diversas, quando não conflitantes, posições que essa instituição vêm tomando em suas decisões e ações em relação à sociedade civil e ao direito de cidadania.

A posição conservadora assumida por parte dos operadores do direito (pelo menos de uma parte), deve-se a um aspecto negligenciado por parte de seus críticos, é destacado por Boaventura de Sousa Santos: a formação da cultura jurídica nas faculdades de direito, de baixa formação teórica e crítica e de "cultura manuelesca". Sousa Santos afirma que diante de uma sociedade complexa, plural, conflitiva e consciente de seus direitos, a nova geração de operadores jurídicos estaria pouco apta para tratar de suas demandas se mantiver como dominante a cultura normativista, técnico-burocrática, assentada em três grandes idéias: a autonomia do direito, a ideia de que o direito é um fenômeno totalmente diferente de tudo o resto que ocorre na sociedade e é autonômo em relação a essa sociedade; uma concepção restritiva do que é esse direito ou do que são os autos aos quais o direito se aplica; e uma concepção burocrática ou administrativa dos processos. (SOUSA SANTOS, 2008: p. 68).

A problemática da judicialização da política e das representações funcionais atinge também as Agências Reguladoras criadas durante o primeiro governo de Fernando Henrique Cardoso a partir do Plano Diretor da Reforma do Estado, sob a coordenação do ex-ministro Luiz Carlos Bresser Pereira quando esteve à frente do Ministério da Administração e Reforma do Estado (MARE). Como observa Edson Nunes, as agências podem assumir distintos estatutos jurídicos, desde sua participação na administração direta, até a sua existência autárquica e independente. A elas competem funções do Executivo, tais como a concessão e fiscalização de atividades e direitos econômicos, e lhes são atribuídas funções do Legislativo, como criação de normas, regras, procedimentos, com força legal sob a área de sua jurisdição. Ademais, ao julgar, impor penalidades, interpretar contratos e obrigações, as agências desempenham funções judiciárias (NUNES at alli, 2007).

Revista Quaestio Iuris, vol.05, nº1. ISSN 1516-0351 p. 256-285 280 
Para Nunes, a formação dessas agências representou a essência da Reforma de Estado dos anos 90. Essa "autarquia especial" tornou-se, como o Ministério Público, um "quarto poder" atuando como um mini Estado dentro do Estado. E, como observa o autor, não existe regulação neutra, tampouco inocente. Nem toda a regulação é contra o regulado. Muitos regulados buscam normas regulatórias que os protejam da competição, que lhes diminuam custos, que criem barreiras de entradas à competição, que os mantenham no mercado, que os protejam de demandas do público. Nem toda regulação, portanto, é a favor do público, ou do regulado. O mercado regulatório é um selvagem campo de lutas de interesses (NUNES et alli, 2007).

Essa visão de múltiplos poderes internos ao Estado converge com a visão de Nicos Poulantzas, citada acima, no que concerne à fragmentação do aparato estatal e as micropolíticas internas em cada instituição do Estado. Essa leitura sociológica sobre o conceito de Estado diverge por completo das visões sistêmicas e normativas, pois percebe que o Estado é uma arena de conflitos internos. E nesse aspecto, tanto o Ministério Público como as Agências Reguladoras possibilitam essa leitura, além de superar a visão tradicional quem predomina no formalismo jurídico sobre a tripartição do poderes e, sobretudo, do princípio que advoga a independência e a harmonia entre eles ${ }^{16}$.

\section{Conclusão}

A emergência dos atores do direito estatal no cenário político brasileiro, como vimos, deveu-se a dois fatores: primeiramente, os dispositivos constitucionais de 1988 que fortaleceram as representações funcionais do direito e, em segundo, a crise de legitimidade das instituições tradicionais da representação política, notadamente os partidos políticos. Soma-se a esses dois fatores o desmantelamento do Estado de Bem-Estar deixando desprotegida ampla parcela da população, e tem encontrado nos juizados especiais e nas

\footnotetext{
${ }^{16}$ Vide o Título I da Constituição Brasileira de 1988 que trata dos Princípios Fundamentais. Para uma crítica a chamada "separação dos poderes" veja os trabalhos de Louis Althusser Montesquieu, a política e a história. São Paulo: Martins Fontes, 1977 e Raymond Aron As etapas do pensamento sociológico, São Paulo: Martins Fontes, 2002 sobre a obra $O$ Espírito da Leis de Montesquieu. Veja também os livros de Kelsen e Poulantzas citados nesse artigo e na bibliografia.
}

Revista Quaestio Iuris, vol.05, $\mathrm{n}^{\circ} 01$. ISSN 1516-0351 p. 256-285 281 


\section{Quaestio Iuris}

vol.05, $\mathrm{n}^{\circ}$ 02. ISSN 1516-0351

defensorias públicas espaços institucionais na defesa de seus direitos sociais. Em meio a esse novo quadro que vem se desenhando nessa década, algumas instituições do direito estatal alcançaram grande projeção na atual conjuntura política, especialmente o Ministério Público e o Supremo Tribunal Federal.

Embora a crescente inserção da judicialização e da representação funcional na vida política nacional tenha provocado intensas críticas, sobretudo no que concerne a seu aspecto elitista e contra-majoritário, e na visão tutelar desses agentes tenham em relação à sociedade civil e ao cidadão "comum", o fortalecimento dessas instituições estatais do direito resultou mais da reação do próprio sistema democrático em face da crise de legitimidade dos canais tradicionais da política diante a própria sociedade. Diferentemente do que os críticos da judicialização e da representação funcional afirmam, já há uma acentuada interação entre a sociedade civil organizada e as instituições do direito estatal, sobretudo nas questões relacionadas aos direitos humanos, consumidor e meio ambiente (MACIEL, 2001; MOTTA, 2008). Não há, como no caso estadunidense apontado por Kalyvas, uma identidade entre os operadores do direito estatal com a ideologia neoliberal, ou, em outras palavras, dos interesses privados.

Há, como observa Sousa Santos, nessas instituições estatais do direito a formação de um campo contra-hegemônico. De acordo com Sousa Santos, "é o campo dos cidadãos que tomaram consciência de que os processos de mudança constitucional thes deram direitos significativos - direitos sociais e econômicos - e que, por isso, vêem no direito e nos tribunais um instrumento importante para fazer reivindicar os seus direitos e as suas justas aspirações a serem incluídos no contrato social.(...) hoje, esses cidadãos têm consciência de que têm direitos e de que esses direitos devem ser respeitados pela sociedade. Nos últimos trinta anos, muitos desses cidadãos organizaram-se em movimentos sociais, em associações. Criando um novo contexto para a reinvindicação dos seus direitos (SOUSA SANTOS, 2008: pp.29-30).”

De fato, as instituições político partidárias perderam o seu oligopólio de representação tendo de conviver com outras formas de representação, tanto as oriundas do próprio Estado (como as do direito), como também da sociedade civil, a exemplo da ongs e as associações de interesses. A política se redefine e modifica o seu significado ao ampliar o leque de seus atores. Ademais, as críticas à judicialização e à representação funcional,

Revista Quaestio Iuris, vol.05, nº1. ISSN 1516-0351 p. 256-285 282 


\section{Quaestio Iuris}

vol.05, $\mathrm{n}^{\circ}$ 02. ISSN 1516-0351

embora justas no que concerne as possibilidades de oligarquização das instituições representativas diante à sociedade, perde o seu foco quando define que o Estado(e as suas instituições) é autônomo, entendido enquanto um sujeito dotado de vontade própria. A perspectiva relacional como a de Poulantzas (1978), ao contrário, entende que qualquer instituição e organização é atravessada pelas contradições e conflitos da sociedade. Assim, distintamente das visões totalizantes e impermeáveis sobre as instituições, o conflito de relações de forças fazem parte da sua materialidade institucional. Desse modo, havendo poder sempre há resistência, e havendo resistência sempre há inversões de forças nos espaços institucionais.

Isso significa dizer que as classes e grupos sociais dominados da sociedade não estão excluídos dentro do aparato estatal, e não obstante não ocupem o papel de dirigentes, ou dominantes, no processo, têm encontrado ressonância em alguns canais institucionais que internalizam as suas demandas dentro do viés legal. Desse modo, realiza-se na democracia brasileira contemporânea uma nova configuração de instituições e atores e que, de certo modo, acabam constituindo novas práticas políticas direcionadas à ampliação dos direitos e de cidadania. Com a crise de algumas instituições modernas como os partidos políticos, as instituições republicanas do direito estatal tornaram-se um espaço para a criação (ou resistência) dos direitos, apesar da possibilidade de sua tendência à oligarquização e ao burocratismo, ou de representação de interesses de setores capitalistas hegemônicos dominantes da sociedade.

\section{Bibliografia}

ARANTES, Rogério Ministério Público e política no Brasil. São Paulo: USP/tese, 2000 .

CARVALHO, José Murilo de. Desenvolvimiento de la ciudadania en Brasil. México: Fondo de Cultura, 1995.

CAPPELLETTI, Mauro. Juizes legisladores? Porto Alegre: Sérgio Antonio Fabris Editor, 1993. 
FEREJOHN, John. "Judicializing politics, politicizing law". Hoover Digest, $\mathrm{n}^{\mathrm{o}}$ 1, 2003.

GARAPON, Antoine. O juiz e a democracia. Rio de Janeiro: Ed. Revan, 1999.

HABERMAS, Jurgen. Teoría de la Acción Comunicativa. Madri: Ed. Taurus Humanidades, 1999.

HIRST, Paul A democracia representativa e seus limites. Rio de Janeiro: Jorge Zahar Editor, 1993.

KALYVAS, Andreas «The stateless theory: Pounlatza's challenge to postmodernism ». In Aronowitz, S. e Bratsis, P. (org.). Paradigm lost: State theory reconsidered. Minnesota: University of Minnesota Press, 2002.

KELSEN, Hans Teoria geral do Direito e do Estado. São Paulo/Brasília: Martins Fontes/ UnB, 1990.

MACIEL, Débora e KOERNER, Andrei "Sentidos da judicialização da política: duas análises". Lua Nova, n 57, 2002.

MACIEL, Débora Alves. "Conflito social, meio ambiente, e sistema de justiça: notas sobre o novo papel do Ministério Público brasileiro na defesa dos interesses difusos", in Plural nº. São Paulo: USP, 2001.

MICHELS, Robert Sociologia dos partidos políticos. Brasília: Ed. UnB, 1982.

MONTESQUIEU, Charles Secondant. O espírito das leis. Brasília. Brasília: Ed. $\mathrm{UnB}, 1982$.

MOTTA, Luiz Eduardo Da justiça caritativa à defesa dos novos direitos: a reconfiguração institucional da Defensoria Pública do Rio de Janeiro. Rio de Janeiro: CEDES/IUPERJ, 2008.

NUNES, Edson et Alli. Agências Reguladoras e Reforma do Estado no Brasil: inovação e continuidade no sistema político-institucional. Rio de Janeiro: Ed. Garamond, 2007.

POUlanTZAS, Nicos Poder Político e Classes Sociais. São Paulo, Ed. Martins Fontes, 1977. L'Etat, le Pouvoir et le Socialisme. Paris: Press Universitaires de France, 1978. 
SADEK, Maria Tereza, «Ministério Público: a construção de uma nova instituição » in OLIVEIRA, Ruben George, RIDENTI, Marcelo e BRANDÃo, Gildo Marçal, A Constitução de 1988 na vida brasileira. São Paulo: ANPOCS/HUCITEC, 2008.

SANTOS, Wanderley Guilherme dos. "Transição em resumo: do passado recente ao futuro imediato". Revista Brasileira de Ciências Sociais, nº 1, 1986.

SILVA, Cátia Aída A Justiça em jogo: novas facetas da atuação dos Promotores de Justiça. São Paulo: Edusp/Fapesp, 2001.

SOUSA SANTOS, Boaventura Para uma revolução democrática da justiça. São Paulo: Cortez, 2008.

SUTIL, Jorge Correa. "Reformas judiciárias na América Latina". In. PINHEIRO, Paulo Sergio et alii (orgs.). Democracia, violência e injustiça. São Paulo: Ed. Paz e Terra, 2000.

TATE, C. Neal e VALLINDER, Torbjon The global expansion of Judicial Power. New York: New York University Press, 1995.

WERNECK VIANNA, Luiz e BURGOS Marcelo Entre princípios e regras (cinco estudos de ação civil pública). Rio de Janeiro: CEDES/IUPERJ, 2005.

WERNECK VIANNA Luiz "O terceiro poder na carta de 1988 e a tradição republicana: mudança e conversão" in OLIVEIRA, Ruben George, RIDENTI, Marcelo e BRANDÃO, Gildo Marçal, A Constitução de 1988 na vida brasileira. São Paulo: ANPOCS/HUCITEC, 2008. 